\title{
GROWTH PAINS
}

\author{
By A. BickerstafF
}

Ottawa, Ontario

With few exceptions, growth data are the most misused, elusive and confusing figures used in the field of technical forestry today. Growth has a present popularity in Canada somewhat akin to that enjoyed by vitamins in the field of nutrition a few years ago.

Everyone wants growth data. Used in the right place, they are just the type of vitamin pills that will give zest and sparkle to the most anaemic management plan, to the most fatuous plea of a conversationist for the preservation of our forest heritage, and to the insistent demand of the "wood butchers" for more wood now. Truly, growth is wonderful.

When used intelligently vitamins play an important part in nutrition; but when used blindly they are of no value and can conceivably have a harmful effect. Similarly forest growth data, when properly determined and applied, are most important and valuable, but when poorly determined and misapplied the claims made for them make the wildest advertising quackery of vitamins pale into insignificance. However, it is not the purpose of this article to go on comparing growth and vitamins ad nauseum; nor is it the purpose to tabulate neatly the various types of growth data, how they are obtained, and how they should be applied; the purpose is chiefly to let off a little steam and air some pet peeves about growth data in general and their application to management plans in particular.

Possibly the greatest perversions of growth data occur in connection with sustained yield forest management. In this field a rather com. mon mystical belief is that the allowable cut is more or less equivalent to the growth. This belief is so common that to many people the words "allowable cut" and "growth" are almost synonymous, to the extent that some otherwise sane foresters say: "The growth for this area is 32 cubic feet per acre, the annual depletion is only 21 cubic feet, therefore, the cut is conservative". Such a conclusion is, of course, utter nonsense. Except in the forester's utopia where "normal" forests attain their optimum development, the resemblance of the allowable cut to any growth figure, gross or net, current or mean, is purely coincidental. In any abnormal forest-and this includes all forests in Canada-the allowable cut depends primarily on how much timber there is to cut, its size and age, and where it is located; the number of cubic feet per acre per year the forest is producing or could produce if it were normal is quite beside the point. At the risk of labouring the obvious, an example or two, simplified to the point of absurdity, might be in order. Assume two properties to have a potential growth or mean annual increment of 30 cubic feet per acre at a rotation age of 100 years. Property " $A$ " is completely stocked with a 20-year stand which is growing vigorously at a current annual rate of 50 cubic feet per acre. Property " $\mathrm{B}$ " is completely stocked with a decadent 200-year old stand which is deteriorating at the current rate of 10 cubic feet per acre. What is the effect of the growth, current or mean, on 
the allowable cut? Obviously the answer is 'none', since an allowable annual cut for sustained yield is impossible in both cases. In the young stand there is no merchantable material to cut, and in the decadent stand any attempt to spread the cut over a whole rotation would result in a tremendous loss of material. The only case where the allowable annual cut for sustained yield is equal to the potential growth capacity of an area is when there is a normal distribution of age-classes on that area. The allowable cut from any sustained yield unit is a definite practical value based mainly on the amount, size, age and location of the material available, and aimed at establishing an approximately normal distribution of age-classes; both the current and potential growth per acre on the unit are mathematical abstractions which are rarely if ever realized in actual cutting.

However, one fundamental figure which might be termed growth is required for almost all plans of regulation. That figure is the rotation, or approximate age at which the stands should be cut. The determination of rotation age can be very simple or very complicated. Possibly the simplest and most accurate method of determining the rotation age for pulpwood species in Eastern Canada is to number forty slips of paper with numbers from 61 to 100 , place them in a hat, mix thoroughly, blindfold the stenographer and have her draw a slip from the hat. The number appearing on the slip represents the age in years at which stands should be cut. This method has the advantage of eliminating all chances of selecting rotation ages of 45 years or 167 years which may be found by the more complicated procedure of drawing yield curves, deriving curves of M.A.I. and C.A.I., and noting the point at which they intersect, (note: the curves may be expressed in either total cubic feet, merchantable cubic feet to various top diameters, cords; for various densities, sites, composition classes, and for stands or individual trees, with or without allowing for mortality or possible thinnings and based on age at either breast height, stump, or total age). The same procedure can be adapted for saw-timber stands by substituting slips of paper numbered from 80 to 120 .

Another figure which rears its ugly head in certain formulas for regulating the annual cut is the mean annual increment at rotation age. Formulas containing this figure are treasured by those who consider Von Mantel's simple formula ${ }^{1}$ too crude for their work since the growth factor is apparently omitted from the formula. Cut formulas containing M.A.I. at rotation age are particularly attractive, since the M.A.I. at this age is fairly easy to determine, and do not call for complete yield tables. Unfortunately such formulas (e.g. Heyer's formula) ${ }^{2}$ require that the M.A.I. be adjusted for the difference between the actual amount of timber on the area and the amount that should be there for sustained yield with present stocking (the Gre or regulated empirical growing stock). The difficulty in getting the Gre is easily overcome by multiplying, in the approved fashion, the M.A.I. by half the rotation to get the Gre. This works out beautifully and gives $1 \quad$ Annual Cut $=$ Actual Growing Stock

$2 \quad$ Annual Cut $=$ M.A.I. $\stackrel{1 / 2 \text { Rotation }}{ \pm}$ Gre-Actual Growing Stock 
results very similar to Von Mantel's formula, in fact, any difference between the two formulas is purely accidental and the result of incorrect addition or multiplication in one or both of the formulas. After having spent considerable time and energy in determining the M.A.I., the writer found this point particularly disconcerting. However, it is very nice to know the M.A.I. for a given area and it certainly adds prestige to a management plan.

Growth data may be used for purposes other than management plans. These uses may be classified under two broad headings: useful and useless.

Under the first heading come fundamental studies of the yield, growth and development of forest stands growing under known conditions, and also comparisons of growth and development of stands cut in different ways or growing under different conditions. This type of work is basic to an understanding of the forest, and its problems cannot be solved in a day or in a year even if every tree in the forest is riddled with increment borer holes made by some modern Diogenes searching with fanatical zeal for the truth about growth. It takes longer than a year and more than an increment borer to find out very much about the way the forest grows. Repeated observations on carefully selected samples seem to be the most realistic approach to the problem at the moment, and all the discussion in the world does not get around the awkward fact that there are very few such samples in Canada.

"Growth for the love of growth" surveys fall conveniently under the general heading of "useless". These might be defined as those studies where somebody wants to know the growth on something but is not quite certain about what the something is or what he wants it for. This definition is a little narrow, since it excludes those who wish to know whether Canada's forests are growing, on an average, at the rate of 15 cubic feet per acre per year, or 40 cubic feet yer year, so that they will know whether or not the forests are growing better in Sweden than they are here. The forester directed to determine the average growth on an area for some such nebulous purpose might perhaps, without sacrificing his professional integrity retire to a comfortable stump and reason: "On this area for which I am supposed to determine the growth, I can get a large number of answers, all of which are substantially correct. Even if I leave out all of the water, bare rock and open muskeg, the current growth will vary between the various sites and types, and on any given site and type will probably vary between 100 cubic feet per acre per year and some negative quantity; because of the age of the timber also, it will be different in ten years time. If I forget about current growth I can determine the potential growth or the growth at rotation age which will be more or less constant for a given site and type. However, to get an average for the whole area I will have to know the rotation age and the relative area of each type and site, and this I don't know. But even if I do get these areas I will still only know the potential growth and this isn't the actual growth or even how much I could cut off this area every year (at this point, a crafty smile steals over the forester's face). I can think of no useful purpose for which this average can be used. Suppose a perfectly healthy patient insisted that his doctor give him some pills, for a non-existent ailment, then the doctor would probably ask him to leave or give him a supply of 
innocuous pills to keep him happy. Now I can't ask my boss to leave but I can give him something harmless. As a result of my past experience with growth, I think that 30 cubic feet per acre per year is a good round figure to use, since it is not so low as to be discouraging nor so high as to be overly optimistic. I will say that the figure applies to the productive forest area without defining the productive forest area, and that it is an average of all sites, types and age-classes, but will omit to say whether or not it is current or mean increment, or merchantable or total increment. This will eliminate presenting a confused set of specific figures which might be misapplied and will be very simple for the general public to understand". From that time onward the growth on that particular property is established at 30 cubic feet per acre, and since the cut is only 20 cubic feet per acre everyone is very happy until one day there is no more timber big enough to cut.

Since there may be some question as to whether there is any point to this article, it might be well, in conclusion, to emphasize three points:

(1) The most important technical requirement for the preparation of a sound sustained yield plan of regulation is a good inventory by species, types, sites and age-classes, from which sufficient information as to growth can be readily derived.

(2) Growth per acre figures are of little value unless precisely defined as to species, type, site, age-class, and as to the method and type of unit employed. Even when this is done, they cannot be applied unless one can determine from inventory data the relatives areas to which the various figures are applicable.

(3) The available growth data of the type just mentioned are extremely limited in Canada and must be obtained on a systematic basis if any true understanding of the growth and development of the forest in important regions is to be acquired. 